\title{
"É como pertencer a um lugar que nunca foi seu." Deportados negociando imobilidade involuntária e condições de retorno a Cabo Verde
}

\author{
Dra. Heike Drotbohm*
}

\section{Introdução}

\begin{abstract}
Nando: Desde que eu cheguei, e agora faz três anos, eu faço de tudo para me lembrar. Eu peço para minha mãe me enviar tênis, meu tipo de camisetas, minha música; eu tento comer macarrão e comida mexicana, ao menos uma vez por mês. Veja, tudo é diferente aqui, eu não sou um turista, eu não escolhi vir aqui. Eu deixei tudo lá, e eu nunca vou poder voltar. E é tão difícil não esquecer.
\end{abstract}

Heike: "Hum! Então, o que você quer dizer quando você fala que quer lembrar de você mesmo; o que é isso?"

Nando: É isso: onde eu sempre estive, onde eu pertenço, onde minha infância está, onde minha 'tribo' está, meus amigos e tudo mais, percebe? Eu não escolhi vir aqui, eu não gosto dessas pessoas. É como pertencer a um lugar que nunca foi seu. Notas de campo, Nova Sintra, Ilha de Brava, $12 / 12 / 2008$.

Eu encontrei Nando ${ }^{1}$ durante meu trabalho de campo em Cabo Verde, uma pequena sociedade insular no oeste africano, onde as subsistências locais estão baseadas, há séculos, na premissa de mobilidade transfronteiriça e conectividade transnacional. Desde sua infância, Nando integrou o grupo dos "móveis" como um migrante, que deixou Cabo Verde, seu local de nascimento há 26 anos,

\footnotetext{
* Phd Dra. Heike Drotbohm Instituto de Etnologia - Universidade Albert-Ludwigs - Freiburg. heike.drotbohm@ethno.uni-freiburg.de

Tradução do texto: Yara Mitsuishi

Revisão Técnica: Ana Cristina Arantes Nasser
} 
juntamente com seus pais e irmãos, e viajou para Brockton, Massachussets, EUA. Ele cresceu na área de Hill Street, onde frequentou o jardim da infância e a escola primária, conquistou a vizinhança junto com seus amigos, e aprendeu a viver sua vida. Contudo, mesmo sendo um "residente legal permanente", portando um green card nos EUA, Nando nunca conseguiu obter a cidadania americana. Morando numa vizinhança particularmente violenta, onde disputas de gangues refletem padrões territoriais, Nando, ainda bem jovem, envolveu-se em brigas de rua com armas e entrou em conflito com a lei. Aos 23 anos, depois de ser capturado pela polícia e após procedimento jurídico, passando aproximadamente 18 meses em diferentes prisões norte-americanas, e novamente esperando vários meses por decisões do Immigration and Naturalization Service [Serviço de Imigração e Naturalização] (INS), Nando foi finalmente transferido de volta a Cabo Verde, um suposto lar longe do lar².

Deportação é um resultado problemático dos modos de vida transnacional. Desde os anos 1990 e especialmente com as consequências de 11/09/2001, o governo dos EUA aprovou várias leis que facilitam a expulsão de não-cidadãos, e por esta razão, mais e mais imigrantes são deportados para seus países de origem. Enquanto para alguns desses retornados a estadia nos EUA durou apenas alguns meses ou poucos anos antes de serem deportados, a maioria passou os anos de formação nos Estados Unidos. Portanto, ao regressar, países como El Salvador, México, Guatemala ou Cabo Verde pareceram para muitos desses retornados como lugares estrangeiros com línguas, códigos de comportamento social e hábitos de consumo não familiares.

Concentrando meu relato no impacto das ações estatais de remoção no país de origem, este artigo complementa outras abordagens que trataram das condições societárias, históricas e políticas de expulsão política (de Genova, 2002; 2007; Nyers, 2003; Peutz \& de Genova, 2010; Walters, 2002) e também contribui com aqueles que contextualizam a deportação em relação à permeabilidade dos campos sociais transnacionais (Hagan et al., 2008; Peutz, 2006; 2007; Quesada, 1999; Zilberg, 2004). O emprego de uma ótica transnacional para analisar os fenômenos de migração nos convida a levar em conta o complexo jogo e as dinâmicas sociais entre nações, Estados e diásporas, os quais têm sido constituídos e definidos pela globalização; enquanto ao mesmo tempo o crescente controle da fronteira do Estado redefine modos de identidade e de pertencimento. Deportação, como veremos aqui, é uma prática de Estado, que tem forte impacto nas condições de vida em outros lugares no mundo.

Nos últimos quinze anos, estudiosos da migração constataram a diversidade de realidades sociais em campos sociais transnacionais. Para um entendimento nuançado das complexidades e dimensões múltiplas do viver simultaneamente incorporado em mais de um Estado-nação, Peggy Levitt e Nina Glick Schiller introduziram a diferenciação entre "modos de ser" de um lado, e "modos de pertencer" de outro (Levitt \& Glick Schiller, 2004). Simplificando, podemos dizer que enquanto "modos de ser" abrangem as relações sociais e práticas 
cotidianas das quais algúem faz parte, sem necessariamente se identificar; "modos de pertencer" se referem a um tipo particular de conhecimento em termos de identidade e consciência de grupo. Portanto, esses termos capturam uma característica particular das vidas dos transmigrantes que vivem diferentes tipos de vínculos, quando inserem suas vidas em mais de uma nação. Além disso, Levitt e Glick Schiller nos lembram que a migração transnacional resulta em entidades sociais heterogêneas e amorfas, não necessariamente configuradas por um fluxo livre de comunicação e viagem, mas sim pela crescente percepção da diversidade e da diferença. Enquanto as pessoas podem viver juntas através de enormes diferenças espaciais, elas entretanto percebem e refletem sobre os diferentes tipos de acesso à mobilidade, os diferentes modos de existência em ambos os lados, as possibilidades de vida contrastantes definindo o viver em diferentes lugares de estar.

O conceito de Levitt e Glick Schiller (2004) fornece uma ferramenta que ajuda a examinar as contraditórias condições de vida dos deportados em Cabo Verde. Nando, por exemplo, no depoimento acima, expressa cautelosamente sua percepção sobre ser forçado a viver em uma situação contraditória e até confusa: enquanto seu local de nascimento e, portanto, seu pertencimento nacional se fixou como um status de cidadania formal em seu passaporte; a sua biografia migrante, seus encontros individuais, suas relações pessoais e seu apego emocional criaram uma sensação de pertencimento, que o liga a um lugar diferente, uma sociedade diferente, uma cultura diferente. É esta inconsistência de estar em um lugar enquanto se pertence simultaneamente a outro, que eu busco investigar neste capítulo.

No texto, me basearei em pesquisa de campo antropológica conduzida em Fogo e Brava, duas pequenas ilhas situadas no sudoeste do arquipélago de Cabo Verde, onde a maioria dos habitantes usualmente associa, para sua subsisitência, o cultivo em pequena escala ou a pescaria ao trabalho sazonal assalariado e às remessas dos migrantes. Nessas duas ilhas, a emigração é predominantemente direcionada aos Estados Unidos. Visto que a deportação é cada vez mais aplicada pelo governo norte-americano, a maioria dos deportados enviados pelos Estados Unidos de volta a Cabo Verde retorna para essas duas ilhas. ${ }^{3}$

Meus encontros com os deportados, na maioria das vezes simplesmente chamados de "DPs" em Cabo Verde, ocorreu durante um projeto maior sobre economias transnacionais cabo-verdianas do cuidado ${ }^{4}$. Além de inserir minha própria vida familiar na rotina diária do cotidiano da ilha, eu me concentrei em várias casas exemplares e biografias de família, bem como em narrativas individuais de diferentes gêneros e faixas etárias. Na maioria das casas, como também no grande público, a situação dos deportados e o problema da deportação constituíam uma questão importante e constantemente debatida em relação às possibilidades futuras de uma subsistência transnacional, como a estabelecida por cabo-verdianos já há séculos. ${ }^{5}$ 


\section{Direitos de Passagem como rito de passagem}

Mobilidade e conectividade global sempre integraram a sociedade caboverdiana e ainda definem o cotidiano das ilhas. 0 transnacionalismo, no caso desta nação insular espalhada não só pelas nove ilhas habitadas, como também por vários países da diáspora, não é nada novo, mas, ao contrário, teve início no século XVI, quando mercadores portugueses que começaram suas vidas nas antigas ilhas habitadas, passaram a acumular uma grande fortuna com o tráfico de escravos, açúcar, algodão e tecidos. O declínio da escravidão no século XVIII resultou em drásticas mudanças econômicas e, com isso, mobilidade espacial e rede global, outrora um privilégio e um acesso ao poder, desenvolvem-se como meios de sobrevivência essencial. Devido ao aumento da população, este país desértico e estéril começou a enfrentar períodos de grave fome durante os anos de seca, e frequentes crises de abastecimento marcaram a vida nas ilhas até os anos 1960. Portanto, a emigração individual de membros da família, bem como o apoio de familiares em outros países, tornaram-se a estratégia de sobrevivência dominante do arquipélago desde cedo (Carreira, 1982). Hoje, a diáspora caboverdiana, encontrada nos Estados Unidos, Portugal, França, Países Baixos, e vários outros países, é mais numerosa do que os $\mathbf{5 0 0 . 0 0 0}$ habitantes das dez ilhas, e o transnacionalismo se tornou o modo de vida dominante (Carling \& Åkesson, 2009).

Da perspectiva dos habitantes, a habilidade do indivíduo em cruzar fronteiras nacionais constitui um fator crucial para a criação de relações sociais e para o desenvolvimento individual. Tendo em conta esse contexto, podemos comparar os direitos de passagem (cruzar fronteiras) com um rito de passagem (no sentido de van Gennep), concedendo reconhecimento social pleno somente para aqueles que ou viajam ou conseguem fazer parte de redes sociais transnacionais. Afora a migração onipresente e imperativa, observamos no mundo todo mudanças recentes no fechamento das fronteiras. A restrição gradual das políticas de imigração tem graves impactos em lugares como Cabo Verde, onde a maioria de uma dada população deseja ou pretende migrar, mas apenas um pequeno número de pessoas o consegue (Carling, 2004). Devido à significância das redes transnacionais, bem como à importância da migração para a efetivação da mobilidade individual e também da coletiva, as dinâmicas entre não-migrantes e migrantes, entre aqueles que ficam e aqueles capazes de se mover, criam novas formas de diferenciação social (Drotbohm, 2009).

Enquanto durante a década de 1980 e 1990 apenas alguns migrantes caboverdianos foram deportados pelos Estados Unidos, ao longo dos últimos dois anos centenas chegaram às ilhas, e hoje, por exemplo, os deportados constituem mais de $2 \%$ da população de Brava. Antigamente, os deportados faziam parte das narrativas de sucesso dos migrantes. A maioria foi integrada por suas famílias ou, em alguns casos, conseguiu obter um visto, ir para o exterior e, com isso, conquistar respeito e aceitação entre aqueles que permaneceram nas ilhas. Mas, no final, eles não foram capazes de corresponder às expectativas das redes sociais transnacionais, alguns nunca conseguiram legalizar sua estadia, outros entraram em conflito com a lei e foram trazidos de volta para seu país de origem, deixando 
para trás toda a sua existência nos Estados Unidos: seus companheiros, pais, irmãos, filhos, seus amigos, seu trabalho, e também, suas conquistas materiais. Agora, de volta, eles têm de conciliar a continuidade de sua cidadania jurídica e o seu pertencimento social e emocional a um distante e (visto que eles não podem retornar legalmente aos Estados Unidos) inatingível lugar de socialização (Drotbohm, 2011a).

\section{Comparando diferentes modos de retorno}

Em várias áreas do mundo, a vida transnacional significa dizer que o retorno - o voluntário e triunfante retorno dos migrantes que conseguiram manter contato com suas famílias no país natal e prover seu bem-estar - é parte de uma afirmação significativa do parentesco transnacional, da solidariedade transfronteiriça e do sucesso familiar (Baldassar, 2001; Potter et al., 2005). Evidentemente, a deportação relacionada ao retorno implica em percepções opostas, e, usualmente, os deportados são recebidos com uma atitude ambivalente, sendo vistos não só como imigrantes fracassados, mas como um desapontamento familiar para todos os parentes no país natal. Ao contrário dos retornados voluntários, que incorporam o bem-sucedido viajante cosmopolita, de grande proveito para aqueles para os quais retorna, os deportados caboverdianos não são capazes de contribuir para a pragmática interna da vida familiar transnacional. Ao contrário, eles absorvem o que era atribuído para aqueles que nunca conseguiram deixar as ilhas, e com os quais eles agora são forçados a permanecer (Carling, 2004; Drotbohm, 2011a). No discurso público, o crescente impacto dos regimes de fronteiras internacionais nos modos de vida local é uma questão constante. Especialmente o fato de que as redes familiares constituem o eixo principal para a efetivação da mobilidade transfronteiriça, enquanto as fronteiras norte-americanas e europeias se fecham, dificultam, ou mesmo impedem futuras oportunidades de conectividade transnacional e migração. Nesse contexto, a remoção forçada de indivíduos, que podem ter servido não só como remetentes de remessas, mas podem ter "constituído" importantes pontos de entrada para seus familiares, é percebida como uma ameaça para a vida cabo-verdiana, tal qual estabelecida há séculos. Portanto, a reação hostil frente aos deportados pode ser explicada parcialmente por essa ameaça sentida pela sociedade cabo-verdiana como um todo.

Além disso, as ambivalências que precedem a chegada de um deportado à casa de seus familiares podem estar relacionadas à falta de informação adequada sobre as razões específicas do seu retorno involuntário. Qualquer deportado, já semanas antes de chegar à casa de seus familiares, vem precedido por informações confusas sobre sua carreira criminal e sua aparência ameaçadora. Independentemente do motivo, se o retorno foi causado pela sentença de uma ofensa criminal ou pelo status de residente não documentado, muitos habitantes das ilhas aderem a essas "narrativas de violência" e contribuem para a imagem do "malandro criminoso", que pode ter a intenção de manter os hábitos antigos, como, por exemplo, o tráfico de drogas ou a cafetinagem. Percepções de diferença 
cultural são também disseminadas entre a população local, indicando o estranho estilo de vida dos deportados, seus hábitos de consumo, sua necessidade de banho diário e sua relutância quanto ao trabalho físico nos campos. Somando-se a esta percepção dos meios de integração social dos deportados, uma das questões mais debatidas é o estilo de se vestir. Tal como Nando, a maioria dos deportados continua a se vestir com suas roupas urbanas americanas, consistindo em calças largas, camisetas largas de basebol com nomes e números de times, bem como um tipo peculiar de bonés de times de basquete usados virados para trás. Como os não-migrantes se vestem preferencialmente com calças mais apertadas e camisetas comuns, eles associam este tipo de moda imediatamente à urbanidade desconhecida da América. Porém, chamou-me a atenção como particularmente entre as novas gerações alguns tentam copiar este estilo de street-wear, seus gestos e movimentos. Muitos jovens cabo-verdianos admiram as experiências dos deportados no exterior, sua aura de ter estado lá, onde eles desejam ir mas não podem. Assim, ao copiar seus comportamentos corporais, eles tendem a chegar perto da materialização daqueles mundos distantes - chamados "merca" em crioulo cabo-verdiano. Portanto, alguns deportados se utilizam da ideologia do retorno, que se desenvolve juntamente com as expectativas e diferenças de status relacionadas à mobilidade transfronteiriça. Na citação abaixo, J.D. reflete sobre seu esquema inicial de um modo alternativo de retorno. Ele diz:

\begin{abstract}
Pra ser sincero, eu realmente gostei, no começo. Eu tinha alguns mil dólares no bolso e, num primeiro momento, foi só uma grande festa. Todas essas garotas... sabe... as garotas cabo-verdianas gostam da gente. Nós somos diferentes dos homens cabo-verdianos. Nós temos boas roupas, boas jóias, nós pagamos por tudo. Eu sempre sonhei em voltar, convidar todo mundo, só para diversão, boa música. Eu fiz isso por algumas semanas, quase dois meses. Depois disso, eles começaram a perguntar: 'quando você vai voltar?'. Daí, meu dinheiro acabou e eles sabiam que eu estava ficando. Eles não perguntam, mas eles sabem. (J.D.)
\end{abstract}

Tal qual J.D., os deportados sabem que têm de negociar seus status entre um ambiente social, que valoriza extremamente a mobilidade, e a migração de retorno. Assim, a importante invenção de J.D., de um modo diferente de retorno, está relacionada às ambivalências de suas percepções entre, de um lado, a excentricidade e a atração, e, de outro, o ciúme, a inveja, ou a rejeição.

\title{
Relacionando modos de ser e modos de pertencer
}

Para entender a perspectiva dos deportados, devemos lembrar que a maioria deles continua sofrendo com o trauma da exposição, detenção e retorno "acompanhado", por até meses e anos depois de sua chegada às ilhas. Especialmente a involuntariedade de sua estadia, como também o sentimento 
de imobilidade, de não poder retornar àqueles lugares familiares, causam a eles frustração e depressão. Por isso, seu comportamento em relação à população local da ilha é marcado, de um lado, por sentimentos ambivalentes de estranhamento e rejeição, e, de outro, pelo desejo de interagir socialmente. Refletindo sobre as memórias das primeiras semanas e meses após o retorno, os DPs entrevistados tendem a ressaltar os sentimentos de estranhamento radical, tendo que "recomeçar a vida do começo. Aprender como falar, como comer, como andar, como vestir" (J.D.). A maioria deles emprega metáforas de infância e desenvolvimento pessoal, para descrever sua absoluta não familiaridade, nos primeiros momentos e dias após a chegada. José, que foi trazido de volta para Cabo Verde há três anos, depois de ter vivido em Boston pelo que considera a sua vida toda, diz:

Quando eu cheguei aqui, eu não sabia nada; não sabia a língua, nada. Quando eu queria algo, uma colher ou qualquer outra coisa, eu tinha que mostrar gestualmente. Eles riam de mim. Por que eu não sabia como pronunciar aquela palavra, eu me sentia como uma criança (José).

Evidentemente, os deportados sentem a intensidade da irritação de diferentes maneiras; e principalmente os que passaram apenas poucos anos em um país estrangeiro não descrevem a fase de chegada como confusão existencial. Contudo, a maioria dos meus entrevistados enfatiza que não voltou, mas sim partiu de um lugar que considerava seu lar (para uma comparação, ver Coutin, 2010). Portanto, eles comparam esse tipo especifico de deslocamento espacial a um retorno no tempo, apartando-os de ganhos e conquistas de que necessitariam para viver uma vida como cidadãos sociais plenos. Em seu trabalho com deportados retornados dos Estados Unidos para El Salvador, Susan Coutin nos lembra que esses sentimentos de alienação também se refletem na documentação da pessoa:

\footnotetext{
Tal alienação assume uma forma quase legal. Tendo sido deportados dos Estados Unidos por serem indocumentados, os deportados também podem, surpreendentemente, deparar-se como indocumentados em El Salvador, seu país de cidadania legal (Coutin, 2010, p.362).
}

Nesse estágio de desorientação fundamental, muitos deportados começam a reavaliar aqueles aspectos da vida que os conectam à antiga sociedade de origem, articulados geralmente em expressões materiais e sensoriais de "pertencimento". Não apenas moda e música, mas também o aroma dos produtos de higiene, assim como a comida, ultrapassam a distância física e conectam seus sentidos ao sentimento do lar. Tal como muitos outros cabo-verdianos que têm família no exterior, os deportados se beneficiam quase regularmente com a chegada de uma quantidade de bidons, velhos barris de gasolina usados por emigrantes para transportar comida e outros tipos de produtos para Cabo Verde; e isso é 
mais do que simplesmente a vinda de alguns itens particulares de consumo. Os deportados, nesses momentos, tentam cultivar a sensação corporal do seu "lar" aportado às encostas da ilha sob a forma de cereal matinal, bolachas de trigo integral, massas e macarrão chinês, videogames, como também camisetas ou sapatos de marcas americanas específicas. Quando perguntado pelas razões de "encomendar" essas comidas americanas de marca, Magno me fala de sua incapacidade de digerir a comida local. "No começo, eu tentei ser educado. Eu não conhecia essas pessoas, então eu comi catxupa e feijoada, todo dia. Mas, daí eu fico com diarreia! Eu preciso da minha própria comida, eu não me sinto bem". E Alexandro, que teve dois filhos com sua nova esposa, desde que voltou a Cabo Verde, me diz:

Quando eu consigo algum dinheiro, eu pego as melhores coisas para colocar na casa. Eu posso fazer cheeseburgers para eles, batatas fritas, eu quero deixá-los americanizados, entende? 'Você não come arroz e feijão na casa do seu pai. Aqui, nesta casa, você come as coisas boas.

A perspectiva de Alexandro deixa claro que a necessidade de expressar pertencimento cultural por meio de afirmações concretas não só reflete o atual estado de sofrimento e distância social, como também revela um aspecto particular de sua alienalidade. Pode parecer contraditório, mas esta articulação da distância social pode eventualmente contribuir para a reintegração social: não só a moda, mas também os produtos que eles recebem e, sobretudo, o cheque mensal da Western Union geram muita inveja entre seus pares locais e os tornam atraentes para as garotas dali. Meus entrevistados estavam bem cientes do fato de que a experiência no exterior os tornou mais atraentes e que eles retornaram mais valorizados, distinguindo-se daqueles "imóveis" que nunca puderam deixar as ilhas. Ao ostentar sua conectividade transnacional, uma estética da diferença cultural e do pertencimento a outro lugar, os deportados lançam mão das ambivalências de alteridade, desempenhando seu status de alguém de fora que, sob diferentes circunstâncias, seria percebido como uma imagem do retornado bem-sucedido e, portanto, valorizado pelos habitantes das ilhas.

\section{Revisitando o ambíguo limite do retorno involuntário}

Torna-se óbvio como a ação estatal de deportação transforma a migração de retorno - um tipo de deslocamento espacial outrora associado ao sucesso do migrante e à ascensão social - em uma experiência mais ambivalente de encontros sociais. Ao observar a sua constante manobra entre o desejo de integração e a distância social, ponderei quais seriam os possíveis caminhos para a sua integração e adaptação. Como demonstrei em outro artigo (Drotbohm, 
2011a), pode ser especialmente difícil para os deportados reestabelecer sua vida profissional, dado que suas habilidades não são aceitas, seu inglês não é desejado, e sua reputação como delinquentes também limita sua aceitação. Portanto, a maioria dos deportados continua dependendo da ajuda financeira de suas famílias no exterior, que tentam compensar as dificuldades deles (e, eventualmente, também seus próprios sentimentos de culpa), enviando-lhes remessas. Afora os parentes próximos, a situação e os destinos dos deportados são examinados de uma maneira mais ponderada por outros migrantes que retornaram voluntariamente, e que geralmente trazem consigo a turbulenta experiência de ter inserido suas vidas em mais de uma localidade. Principalmente, aposentados e homens de negócios, mas também visitantes e turistas em Cabo Verde, expressam preocupação e compaixão ao discutir a situação e o futuro da vida dos deportados, quando a questão de uma eventual "justeza" da deportação dificilmente parece importar. Especialmente os chamados cosmopolitas, aqueles que podem viajar facilmente para outros países, advertem contra os perigos de definir o valor moral de uma pessoa em termos de livre deslocamento versus retorno involuntário. Uma vendedora, por exemplo, que visita as ilhas regularmente, e ajuda um deportado bancando sua pequena loja de aparelhos eletrônicos, comenta o seguinte: "As pessoas, aqui, não sabem nada das nossas vidas nos Estados Unidos. Na verdade, hoje em dia está cada vez mais difíil não ser retornado. Os tempos estão diferentes, e os cabo-verdianos têm de se acostumar com isso."

Esta citação é típica entre muitos cabo-verdianos que entrevistei, tanto nas ilhas quanto na diáspora, e que refletiram sobre as mudanças das condições de vida em campos transnacionais. Além do impacto do fechamento das fronteiras (Carling, 2004), também o controle dos indocumentados na diáspora e a produção da "ilegalidade", "deportabilidade" e "detencionabilidade" do migrante (De Genova, 2007) são percebidos de modo particularmente forte por caboverdianos, cujo sentimento de identidade e de pertencimento estava ligado, ao longo de alguns séculos, à mobilidade transatlântica e à conectividade (Halter, 1993; Fikes, 2009). Durante os vários últimos anos, a realização da mobilidade transfronteiriça, outrora uma via segura para a melhoria econômica, tornou-se uma experiência de crescente adversidade e confrontação com a ausência de direitos (De Genova, 2007). Vista sob esta luz, a deportação constitui um perigo possível para muitos transmigrantes, que tentam se apegar a um modo de vida transnacional, mas precisam se conscientizar dessa nova era de retorno forçado e de novos tipos de imobilidade.

Por fim, a experiência de Carlos, que é proprietário do único posto de gasolina em Nova Sintra, principal cidade de Brava, também contribui para um entendimento mais complexo do nexo entre mobilidade, identidade e pertencimento, no contexto da deportação. Em uma conversa informal no caixa do posto, ele relata: 
Carlos: Sabe, as pessoas pensam que eu sou bem-sucedido aqui em Nova Sintra; eu sou dono deste posto, da garagem $e$ de outras coisas, as pessoas me procuram para pedir dinheiro emprestado e etc. Mas, veja: eu também poderia me chamar de 'deportado', eu deportei a mim mesmo, em um certo sentido. Isso foi num momento em que eu sabia que iria ter problemas nos Estados Unidos: eles são simplesmente loucos por controle.

Heike: "Você teve problemas com a lei?"

Carlos: Não, isso não aconteceu; foi apenas uma intuição sábia sobre as possibilidades, eu sabia que iria acontecer um dia. E eu não posso me esquecer disso. Nós temos que permanecer humildes.

Heike: "Então, como você fez quando voltou?"

Carlos: no começo, quando eles entenderam que eu não voltaria para o exterior, eles disseram que eu também era um deportado. Mas foi somente porque, veja, eu gosto do modo de vida americano, o jeito de se vestir e tudo mais. Um tio me aconselhou a me vestir mais formalmente e foi isso que eu fiz: calças justas, camisas de algodão, e etc. Ele me ajudou a comprar esse posto de gasolina, e foi isso.

A situação de Carlos nos lembra do fato de que o limite entre os deportados, de um lado, e os retornados voluntários, de outro, não pode ser traçado tão claramente como parece à primeira vista. Além daqueles que se "autodeportaram" em momentos em que o confronto com os procedimentos jurídicos era iminente, outros também retornaram aparentando involuntariedade. Durante a minha estadia em Boston, em setembro de 2008, muitos migrantes cabo-verdianos se preocupavam com os novos riscos da crise econômica e financeira mundial, que atingiu especialmente esses grupos sociais, cujas condições de permanência, trabalho ou moradia não eram $100 \%$ definidas. Portanto, a direção e as condições do deslocamento, bem como a demonstração de lealdade cultural, servem como sinais importantes e simbolicamente ricos, usados por membros de campos sociais transnacionais para repensar esses desafios mais recentes da globalização.

\section{Conclusão}

Os aspectos etnográficos aqui expostos dão insights sobre o tecido social de uma sociedade insular fundamentalmente definida por uma vida transnacional, em que a particular contra-tendência de mobilidade transfronteiriça produz, 
simultaneamente, consternação, rejeição, vulnerabilidade e admiração. Ao buscar entender a dinâmica entre o acesso à mobilidade transfronteiriça e as identidades transnacionais, chegamos à conclusão de que "modos de ser" e "modos de pertencer", como descritos por Levitt e Glick Schiller (2004), não só diferem, nesses casos, como também fundamentalmente se excluem. Enquanto os deportados tentam estabelecer seus modos de ser em Cabo Verde e refletem sobre suas capacidades e possíveis contribuições para a sociedade na qual eles permanecem "estrangeiros", seu não pertencimento não pode ser ignorado; pelo contrário, seus modos de pertencimento social e cultural os remetem de volta à diáspora e, portanto, a um Estado-nação que, de novo e simultaneamente, articula seu não pertencimento. Em seu livro intitulado The situated politics of belonging (2006), Yuval-Davis, Kannabiran e Vieten descrevem as tendências políticas e culturais dessa era da globalização, como:

\section{[...] frequentemente entrelaçadas em construções ideológicas que naturalizam, essencializam e fixam fronteiras de coletividade, hierarquias de 'civilizações' e de poder. Essas fixicidades são usadas para defender e promover posições privilegiadas de poder, bem como mecanismos de defesa pessoal e comunal dos muitos que se sentem ameaçados e privados pelos mesmos processos (Yuval-Davis, 2006, p.1).}

Portanto, ao lidar com essas novas fixicidades e mecanismos de defesa coletiva, os deportados chegam a entender que cultivar os laços sociais através de grandes distâncias é crucial para a sua própria sobrevivência. Mesmo sabendo do seu essencial grau de exclusão, os deportados logo se conscientizam do fato de que eles são também retornados e, portanto, têm igualmente uma posição privilegiada, com acesso a capital social e econômico, ostentando um American way of life, sua antiga mobilidade. A micropolítica do cotidiano local revela que a mobilidade, nesses casos, tem produzido uma qualidade imaginária, uma brisa de cosmopolitismo envolvendo seus antigos movimentos, seus gestos, seu estilo, sua alimentação, seus hábitos. Além disso, entre o grupo dos "móveis", que tiveram a oportunidade de retornar (em parte) voluntariamente, o destino dos deportados serve como um lembrete das contingências imprevisíveis dessa mais recente fase de globalização, como também dos riscos compartilhados da vida transnacional. Portanto, a demonstração ostensiva das inconsistências culturais, bem como o não esquecimento dos simultâneos modos de pertencer produzem, ao menos em certas partes desse novo e não familiar ambiente, reconhecimento social, compaixão e integração. 


\section{Notas:}

1 - Para proteger a privacidade dos indivíduos pesquisados, eu usei nomes comuns como pseudônimos.

2 - Apesar da transnacionalização de estudos de migração, os termos "lar" (home) ou país de "envio", por um lado; e, "destino" ou pais de "recebimento", por outro, continuam apropriados para descrever a condicionalidade e a direção espacial da migração. Contudo, no contexto de deportação, tais termos são invertidos: "lar" não é mais o anterior país de destino, e o "país de recebimento" se torna o antigo país de origem.

3 - De acordo com os dados estatísticos de 2008, fornecidos pelo Instituto das Comunidades do Ministério dos Assuntos Estrangeiros, Cooperação e Comunidades, de Cabo Verde, o número de deportações tem aumentado anualmente, começando com cinco em 1992 e alcançando o ponto máximo em 2007, com 128 deportados registrados oficialmente. Até 2002, Portugal era o país que enviava de volta o maior contingente; mas, a partir de 2002, a maioria tem sido retornada pelos Estados Unidos. Em 2007, 50\% dos deportados foram enviados de volta dos Estados Unidos, 33\% de Portugal, 8\% da França, e o resto da Espanha, Luxemburgo, Alemanha e Brasil. Daqueles que retornaram a Brava, $100 \%$ vieram dos Estados Unidos; dos que voltaram para Fogo, 83\% retornaram dos Estados Unidos e 17\% de Portugal. A proporção de mulheres deportadas sempre foi abaixo de $5 \%$. Além disso, é importante notar que apenas uma minoria de deportados são registrados no momento de sua entrada em Cabo Verde. Portanto, estimativas do número real de deportados devem ser consideravelmente mais altas (Instituto das Comunidades, 2008).

4 - Helena Hirata, em seu livro Cuidado e Cuidadoras: as várias faces da economia do care. (São Paulo, Editora Atlas, 2012) mantém o termo "care" em inglês para se referir à economia do cuidado: atividade do setor de serviços, em grande expansão em escala internacional, voltada ao cuidado domiciliar de idosos, crianças, deficientes físicos e doentes (NT).

5 - Veja também Drotbohm (2011b), para uma análise da percepção da deportação na comunidade haitiana em Montreal, Canada.

\section{Referências Bibliográficas}

BALDASSAR, L. Visits home: migration experiences between Italy and Australia. Melbourne: Melbourne University Press, 2001.

CARLING, J, ÅKESSON, L. Mobility at the heart of a nation. Patterns and meanings of Cape Verdean migration. International Migration, 47 (3), p. 123-155, 2009.

CARLING, J. Emigration, Return and Development in Cape Verde: The Impact of Closing Borders. Population, Space and Place, 10 (2), p. 113-132, 2004.

CARREIRA, A. The people of the Cape Verde Islands: exploitation and emigration. C. Fyfe trans. Hamden, CT: Archon, 1982.

COUTIN, S. B. Exiled by Law: Deportation and the Inviability of Life. In: N. DE GENOVA AND N. PEUTZ (eds.). The deportation regime. Sovereignty, space, and the freedom of movement. Durham e Londres: Duke University Press, 2010, p. 351-371.

DE GENOVA, N. Migrant 'illegality' and deportability in everyday-life. Annual Review of Anthropology, 31, p. 419-447, 2002. 
DE GENOVA, N. The production of culprits: from deportability to detainability in the aftermath of homeland security. Citizenship Studies, 11 (5), p. 421-448, 2007.

DROTBOHM, H. Horizons of long-distance intimacies. Reciprocity, contribution and disjuncture in Cape Verde. History of the Family, 14 (2), p. 132-149, 2009.

DROTBOHM, H. On the durability and the decomposition of citizenship: The social logics of forced return migration in Cape Verde. Citizenship Studies, 15 (3/4), xxx, $2011 \mathrm{a}$.

DROTвOHM, H. (2011b) Deporting Diaspora's Future? Forced Return Migration as an Ethnographic Lens on Generational Differences among Haitian Migrants in Montreal. In: JACKSON, R (ed.) Geographies of the Haitian Diaspora. Oxford, Nova lorque: Routledge. S. p. 185-204, 2011b.

FIKES, K. Managing African Portugal. The Citizen-Migrant Distinction. Durham e Londres: Duke, 2009.

HAGAN, J, K. ESCHBACH e N. RODRIGUEZ. U.S. Deportation Policy, Family Separation, and Circular Migration. International Migration Review, 42 (1), p. 64-88, 2008.

HALTER, M. Between Race and Ethnicity: Cape Verdean American Immigrants, 1860-1965. Chicago: University of Illinois Press, 1993.

INSTITUTO DAS COMUNIDADES (Análise dos dados do recenseamento dos repatriados. Unpublished project report of the Instituto das Comunidades, Ministério dos Negócios Estrangeiros, Cooperação e Comunidades. Praia, 2002.

INSTITUTO DAS COMUNIDADES. Análise dos dados do recenseamento dos repatriados. Unpublished project report of the Instituto das Comunidades, Ministério dos Negócios Estrangeiros, Cooperação e Comunidades. Praia, 2008.

LEVITT, P. e N. GLICK SCHILLER. Conceptualizing Simultaneity: A Transnational Social Field Perspective on Society. International Migration Review, 38 (145), p. 595-629, 2004.

NYERS, P. Abject cosmopolitanism: the politics of protection in the anti-deportation movement. Third World Quarterly, 24 (6), p. 1069-1093, 2003.

PEUTZ, N. Embarking on an anthropology of removal. Current Anthropology, 47 (2), p. 217241, 2006.

PEUTZ, N. Out-laws: deportees, desire, and "the law". International Migration, 45 (3), p. 182191, 2007.

PEUTZ, N. e DE GENOVA, N. Introduction. In: N. De Genova and N. Peutz, eds. The deportation regime. Sovereignty, space, and the freedom of movement. Durham e Londres: Duke University Press, 2010, p. 1-32.

POTTER, R. B.; D. CONWAY; J. PHILLIPS (eds.). The experience of return migration: Caribbean perspectives. Burlington, Vermont: Ashgate, 2005.

QUESADA, J. From Central American Warriors to San Francisco Latino Day Laborers: Suffering and Exhaustion in a Transnational Context. Transforming Anthropology, 8 (1\&2), p. 162185, 1999.

WALTERS, W. Deportation, Expulsion, and the International Police of Aliens. In: Citizenship Studies, 6 (3), p. 265-292, 2002. 
VAN GENNEP, Arnold. Les rites de passage. Paris: Nourry, 1909.

YUVAL-DAVIS, N, K. KANNABIRAN e U. VIETEN (2006) Introduction. Situating Contemporary Politics of Belonging. In: N. YUVAL-DAVIS, K. KANNABIRAN and U. VIETEN (eds.). The situated politics of belonging. Londres: Sage, 2006, p. 1-16.

ZILBERG, E. Fools banished from the kingdom: remapping geographies of gang violence between the Americas (Los Angeles and San Salvador). American Quarterly, 56 (3), p. 759-779, 2004.

\title{
RESUMO
}

Baseado em pesquisa antropológica em Cabo Verde, um pequeno país insular no oeste africano, este capítulo trata da deportação de migrantes não cidadãos e seu retorno involuntário para seus países de origem. Esta ação estatal atualmente constitui um elemento importante na conexão de sociedades e práticas estatais principalmente na Europa ou na América do Norte, com a subsistência no chamado Sul Global. Enquanto alguns desses migrantes deportados permaneceram nos países de destino por alguns meses ou anos, antes de serem retornados pela força do Estado, muitos passaram os anos de formação no exterior. Portanto, no dia de sua chegada, seus países de origem pareceram lugares estrangeiros, com línguas, códigos de conduta social e hábitos de consumos não familiares. Este artigo aborda o modo específico de retorno dessas pessoas, seus esforços de reintegração, suas habilidades em utilizar as experiências de migração anteriores para construir novas relações sociais, e sua renegociação de pertencimento em campos sociais transnacionais.

Palavras chaves: deportação, migração de retorno, Cabo Verde.

\begin{abstract}
Based on anthropological research in Cape Verde, a small West-African island state, this chapter deals with the deportation of migrant non-citizens and their involuntary return to their countries of origin. This state act currently constitutes an important element in connecting societies and state practices, situated mainly in Europe or North America, with livelihoods in the so-called Global South. While some of these deported migrants had only remained in countries of destination for some months or years before being returned by state force, many had spent their formative lifetime abroad. Hence, their alleged home countries on the day of their arrival appeared as foreign places with unfamiliar languages, codes of social behavior, and habits of consumption. This article deals with their particular mode of return, their efforts to re-integrate, their abilities to draw on their former experiences of migration for building new social relationships and their renegotiation of belonging in transnational social fields.
\end{abstract}

Key words: deportation; return migration; Cape Verde. 